\title{
Aplikasi Sensor TGS2620 dan MQ138 untuk Mendeteksi Kematangan Buah Durian Berbasis Raspberry Pi 3B
}

\author{
Dewi Puspitasari $^{(a) *}$, Arif Surtono ${ }^{(b)}$, Sri Wahyu Suciati ${ }^{(c)}$, Gurum Ahmad \\ Pauzi ${ }^{(d)}$ \\ Jurusan Fisika Fakultas Matematika dan Ilmu Pengetahuan Alam (FMIPA), Universitas Lampung, Bandar \\ Lampung, 35141 \\ *email: ${ }^{\left(a^{*}\right)}$ dewipuspita1060@gmail.com,arif.surtono@fmipa.unila.ac.id,sri.wahyu@fmipa.unila.ac.id, \\ gurum@fmipa.unila.ac.id
}

Diterima (16 Maret 2021), Direvisi (28 Juli 2021)

\begin{abstract}
Research has been carried out by application of the TGS 2620 (alcohol level) and MQ 138 (methane level) gas sensors to detect the maturity of durian based on Raspberry Pi 3b. This research was conducted to produce a detection instrument for the level of durian maturity. Durian is inserted into the sample room which contain a gas sensors. The classification method used to determine fruit maturity uses $K$ Nearest Neighbor (KNN). The KNN test in the durian maturity classification using a gas sensor has accuracy based on maturity level, ripe 93,3\%; rare $96.6 \%$; raw $93,3 \%$
\end{abstract}

Keywords: Maturity of durian, gas sensor, raspberry pi 3b, KNN.

\begin{abstract}
Abstrak. Telah dilakukan penelitian dengan pengaplikasian sensor gas TGS 2620 (kadar alkohol) dan MQ 138 (kadar metana) untuk mendeteksi kematangan buah durian berbasis Raspberry Pi 3b. Penelitian ini dilakukan untuk menghasilkan alat deteksi tingkat kematangan buah durian. Durian diletakkan ke dalam ruang sampel yang berisi sensor gas. Metode klasifikasi yang digunakan untuk menentukan kematangan buah menggunakan K-Nearest Neighbor (KNN). Pengujian KNN dalam klasifikasi kematangan durian menggunakan sensor gas memiliki akurasi berdasarkan tingkat kematangannya, yakni matang 93,3\%; setengah matang $86,6 \%$; mentah $93,3 \%$.
\end{abstract}

Kata kunci: Kematangan, durian, sensor gas, raspberry pi 3b, KNN,.

\section{PENDAHULUAN}

Durian menjadi buah yang paling digemari konsumen Indonesia maupun mancanegara. Wilayah Indonesia khususnya Lampung yang menjadi produsen durian antara lain Desa Talang Kabupaten Pesawaran [1], Pesawaran Indah Kecamatan Padang Cermin [2], Wisata Durian Kelurahan Sumber Agung [3], Harapan Baru I Kelurahan Batu Putuk Bandar Lampung [4], dan Kecamatan Pekalongan Kabupaten Lampung Timur[5].

Kebanyakan genus Durio tidak berbau atau lemah, namun spesies Durio dulcis sangat kuat baunya bahkan dapat tercium hingga jarak yang cukup jauh [6]. Ciri-ciri buah yang matang akan menunjukkan beberapa tanda yakni, umur durian yang mencapai tingkat kematangan penuh, yaitu pada minggu ke 16 [7], buah yang dipotong dari tangkainya dilakukan pada sekitar umur 105 hari sesudah antesis [8], perubahan warna kulit walaupun hanya sedikit berubahnya [9], dan aroma buah atau dengan bunyi nyaring ketika buahnya diketuk-ketuk [10]. Beberapa teknik pengembangan metode deteksi kematangan 
buah durian dengan e-nose seperti deret sensor gas semikonduktor yakni TGS 2602, TGS 813, TGS 2611, TGS 2600, dan TGS 2612 telah digunakan untuk identifikasi kematangan buah tropika yakni jeruk, stroberi, dan tomat [11]. Sensor gas TGS 2620 dan TGS 2600 untuk deteksi kematangan durian [12]. Dari beberapa penggunaan e-nose yang telah digunakan pada penelitian sebelumnya, sensor gas jenis TGS dan MQ 138 adalah yang paling baik penggunaannya karena dapat mendeteksi gas dengan cepat dan jarak yang jauh[13].

Sebagai upaya untuk meminimalisir terjadinya error dan meningkatkan ketepatan klasifikasi durian, maka pada penelitian ini digunakan dua jenis sensor yakni TGS 2620 dan MQ138. Teknik yang digunakan dalam penelitian ini memiliki keunggulan dengan tidak merusak buah. Sensor dipasang pada sisi bawah bawah pada chamber yang juga akan berisi durian, sehingga sensor mudah mendeteksi gas pada durian. Metode klasifikasi yang digunakan dalam penelitian ini adalah KNN (K-Nearest Neighbor). Metode ini dipilih karena lebih tepat penggunannya untuk masing-masing sensor hanya mendeteksi satu jenis gas, yakni gas alkohol pada TGS 2620 dan gas metana MQ 138

Adapun tujuan dari penelitian ini yaitu menghasilkan alat deteksi tingkat kematangan buah durian menggunakan sensor TGS 2620 dan MQ 138 berbasis Raspberry Pi 3b dan mengetahui hubungan senyawa gas (bau) yang dideteksi oleh sensor terhadap tingkat kematangan durian.

\section{METODE PENELITIAN}

Alat dan bahan yang digunakan dalam penelitian ini adalah Personal Computer (PC), multimeter, raspberry pi $3 \mathrm{~b}$, logic level converter, LCD I2C $20 \times 4, \mathrm{PCB}, \mathrm{MCP}$ 3008 , kabel jumper, power supply 12volt, refractometer atago PAL- $\alpha$, solder, timah, kotak, kipas DC, TGS2620, MQ138, durian, silica gel, dan aquades.

Langkah pertama: pengumpulan data latih ini berguna untuk acuan tingkat kematangan durian. Data yang pertama dicari adalah nilai ppm gas durian yang diambil dari sensor gas TGS 2620 dan MQ 138. Pengambilan sampel dilakukan sebanyak 5 kali perulangan pada 1 buah durian dari 6 durian.

Langkah kedua : sebagai referensi atau pembanding data pembuktian bahwa durian tersebut matang, setengah matang, atau mentah dilakukan pengujian glukosa dengan menggunakan Refraktometer Atago Pal- $\alpha$. Dalam pengujiannya, urutan daging durian yang akan diambil sampelnya disesuaikan dengan urutan durian dalam pengambilan kadar gas. Daging durian yang diambil sampelnya adalah bagian tengah yang lembut. Selanjutnya daging durian tersebut dihaluskan. Setelah halus kemudian diambil sedikit sampel untuk diletakkan di titik sampel pengujian pada Refraktometer[14]. Pengambilan sampel dilakukan sebanyak 3 kali perulangan pada 1 buah durian dari 6 durian.

Langkah ketiga : melakukan pengujian sistem. Pengujian kematangan menggunakan 3 buah durian berbeda yang baru. Dilakukan 5 kali perulangan setiap 1 buah durian.

\section{HASIL DAN PEMBAHASAN}

Telah direalisasikan pengaplikasian sensor gas TGS 2620 dan MQ 138 untuk mendeteksi kematangan durian berbasis raspberry pi $3 b$. Alat ukur yang digunakan untuk menganalisis kematangan durian terdiri dari kipas, kotak alat, sensor dan LCD I2C. Realisasi alat seperti pada Gambar 1. 


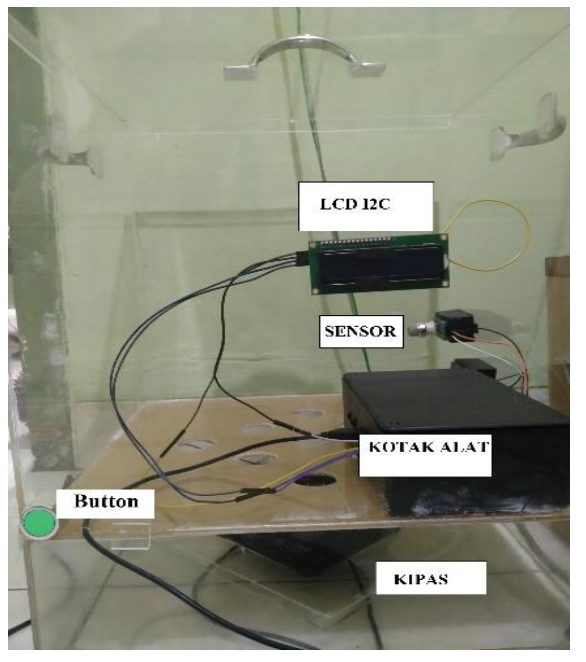

Gambar 1. Realisasi alat

Cara kerja dari alat ini yaitu sampel durian ini dimasukkan ke dalam ruang pengujian, kemudian diakuisisi data oleh program yang dibuat. Hasil dari akuisisi data tersebut ditampilkan pada LCD.

\section{Pengambilan Data Latih}

Pengumpulan data latih ini berguna untuk acuan tingkat kematangan durian. Data yang pertama dicari adalah nilai ppm gas durian yang diambil dari sensor gas TGS 2620 dan MQ 138. Data latih tersebut disimpan dan untuk referensi atau pembanding data pembuktian bahwa durian tersebut matang, setengah matang, atau mentah dilakukan pengujian glukosa dengan menggunakan Refraktometer Atago Pal- $\alpha$. Dalam pengujiannya, urutan daging durian yang akan diambil sampelnya disesuaikan dengan urutan durian dalam pengambilan kadar gas. Diambil sedikit sampel untuk diletakkan di titik sampel pengujian pada Refraktometer Realisasi pengujian dapat dilihat pada Gambar 2.

Data hasil pengujian kadar glukosa dapat dilihat pada Tabel 1. Berdasarkan Tabel 1 dapat diketahui durian matang memiliki kadar glukosa yang tinggi yakni $32 \%-42 \%$.

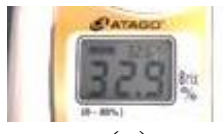

(a)

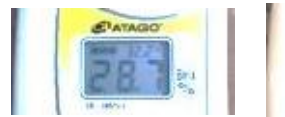

(b)

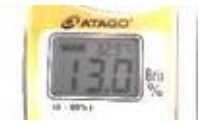

(c)
Gambar 2. Pengujian kadar glukosa pada durian (a) matang, (b) setengah matang dan (c) mentah

Hasil dari data pelatihan dimasukkan kedalam grafik sebaran data latih yang dapat dilihat pada Gambar 3 . Pada gambar tersebut, sensor gas TGS 2620 dan MQ 138 terlihat lebih sensitif terhadap durian yang matang, sebaran data durian yang matang terlihat berjarak. Sedangkan untuk durian yang mentah dan setengah matang sebaran data gas nya terlihat tidak jauh berbeda, sehingga sebaran datanya terlihat menimpa. Berdasarkan data latih, data sensor TGS 2620 dan MQ 138 dimasukkan kedalam grafik yang terdapat pada Gambar 4 untuk dilihat perbandingan kedua sensor dalam hasil pendeteksian masing-masing gas.

Tabel 1. Pengujian kadar glukosa durian

\begin{tabular}{lcc}
\hline Pengulangan & $\begin{array}{c}\text { Kadar } \\
\text { Glukosa }(\%)\end{array}$ & Keterangan \\
\hline A1 & 32,9 & Matang \\
A2 & 42,8 & Matang \\
A3 & 37,6 & Matang \\
B1 & 35,7 & Matang \\
B2 & 32,6 & Matang \\
B3 & 33,5 & Matang \\
C1 & 24,2 & Setengah Matang \\
C2 & 28,7 & Setengah Matang \\
C3 & 25,8 & Setengah Matang \\
D1 & 23,6 & Setengah Matang \\
D2 & 24,7 & Setengah Matang \\
D3 & 28,4 & Setengah Matang \\
E1 & 21,6 & Mentah \\
E2 & 13,0 & Mentah \\
E3 & 16,5 & Mentah \\
F1 & 18,7 & Mentah \\
F2 & 14,5 & Mentah \\
F3 & 15,8 & Mentah \\
\hline
\end{tabular}




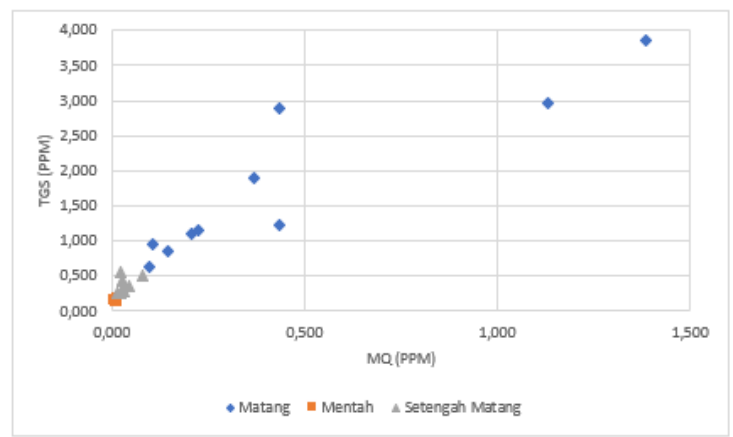

Gambar 3. Grafik sebaran data latih

Pada sumbu "x" Gambar 4, merupakan urutan kematangan durian, yakni 1-10 durian matang, 10-20 durian setengah matang, 11-30 durian mentah. Pada sumbu "y" merupakan gas yang dideteksi masing-masing sensor. Pada gambar tersebut, terlihat bahwa kandungan gas alkohol yang dideteksi sensor TGS 2620 lebih tinggi dibandingkan dengan gas metana yang dideteksi sensor MQ138 pada durian. Kandungan gas tersebut akan meningkat saat durian dalam kondisi matang. Hal ini sesuai dengan teori bahwa durian memiliki kandungan gas alkohol dan bis(ethylthio)methane yang akan semakin kuat aromanya seiring proses kematangan buahnya[15].Setelah diketahui karakteristik data durian dari data latih dan Tabel 1. Maka selanjutnya menguji data dengan menggunakan metode $\mathrm{KNN}$, yakni data yang baru akan dikelompokkan berdasarkan sebaran data tetangga terdekatnya. Realisasi pengujian dapat dilihat pada Gambar 5.

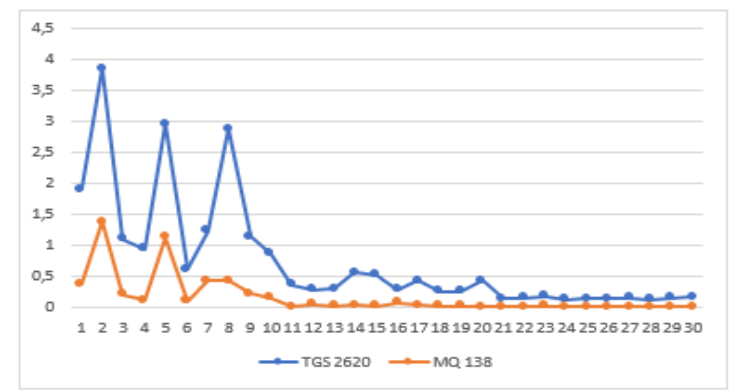

Gambar 4. Perbandingan sensor gas TGS 2620 dan MQ 138

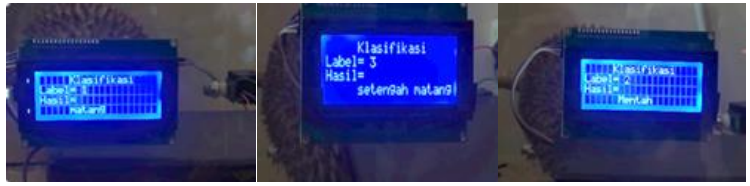

(a)

(b)

(c)

Gambar 5. Realisasi pengujian (a) matang, (b) setengah matang, dan (c) mentah

Setelah durian dimasukkan kedalam ruang sampel dan dideteksi kematangannya, hasil perolehan data tersebut disajikan pada Tabel 2. Pada pengujiannya, proses running klasifikasi durian membutuhkan waktu sekitar 3 menit. Pada pengujiannya, proses running klasifikasi durian membutuhkan waktu sekitar 3 menit. Hal ini dikarenakan looping yang digunakan untuk mendeteksi gas durian sebanyak 250 kali dalam prosesnya. Pengulangan tersebut dilakukan untuk menunjang performa sensor MQ 138 yang kurang sensitif terhadap gas yang dideteksi pada durian. Pengujian kematangan durian menggunakan 3 buah durian yang berbeda yakni $\mathrm{A}, \mathrm{B}$, dan $\mathrm{C}$ dengan 5 kali pengulangan pada masing-masing variabel.

Tabel 2. Hasil pengujian

\begin{tabular}{lccc}
\hline Pengulangan & KNN & Referensi & Hasil \\
\hline A1 & Mentah & $\begin{array}{c}\text { Setengah } \\
\text { matang }\end{array}$ & Gagal \\
A2 & Setengah & $\begin{array}{c}\text { Setengah } \\
\text { matang }\end{array}$ & Berhasil \\
& Setengah & Setengah & Berhasil \\
A3 & matang & matang & \\
& Setengah & Setengah & Berhasil \\
A4 & matang & matang & \\
& Setengah & Setengah & Berhasil \\
A5 & matang & matang & \\
& Mentah & Mentah & Berhasil \\
B1 & Mentah & Mentah & Berhasil \\
B2 & Mentah & Mentah & Berhasil \\
B3 & Mentah & Mentah & Berhasil \\
B4 & Mentah & Mentah & Berhasil \\
B5 & Matang & Matang & Berhasil \\
C1 & Setengah & Matang & Gagal \\
C2 & Matang & & \\
& Matang & Matang & Berhasil \\
C3 & Matang & Matang & Berhasil \\
C4 & Matang & Matang & Berhasil \\
C5 & & & \\
\hline
\end{tabular}


Tabel 3. Confussion matrix

\begin{tabular}{cccc}
\hline Kelas & \multicolumn{3}{c}{ Kelas Prediksi } \\
\cline { 2 - 4 } Sebenarnya & Kelas 1 & Kelas 2 & Kelas 3 \\
\hline Kelas 1 & 4 & 0 & 1 \\
Kelas 2 & 0 & 5 & 0 \\
Kelas 3 & 0 & 1 & 4 \\
\hline
\end{tabular}

Keterangan:

Kelas 1 : merupakan kelas matang.

Kelas 2 : merupakan kelas mentah.

Kelas 3 : merupakan kelas setengah matang.

Data tersebut dimasukkan kedalam tabel confussion matrix seperti pada Tabel 3. Pada Tabel 3, kelas matang pada saat diprediksi memiliki kesesuaian data dengan kelas sebenarnya sebanyak 4 dan tidak sesuai sebanyak 1 (masuk ke dalam kelas setengah matang). Kelas mentah memiliki kesesuaian data dengan kelas sebenarnya sebanyak 5 dan tidak ada data yang tidak sesuai. Kelas setengah matang memiliki kesesuaian data dengan kelas sebenarnya sebanyak 4 dan tidak sesuai sebanyak 1 (masuk ke dalam kelas mentah).

Dari tabel confusion matrix dapat dihitung parameter akurasi dan prediksi keseluruhan dari setiap kelas, yang dapat dilihat seperti pada Tabel 4.

Tabel 4. Binary confussion matrix

\begin{tabular}{|c|c|c|c|c|}
\hline Kelas & \multicolumn{2}{|c|}{ Kelas Prediksi } & \multirow{2}{*}{$\begin{array}{c}\text { Akurasi } \\
(\%)\end{array}$} & \multirow{2}{*}{$\begin{array}{c}\text { Presisi } \\
(\%)\end{array}$} \\
\hline & Kelas 1 & $\begin{array}{l}\text { Bukan } \\
\text { kelas 1 }\end{array}$ & & \\
\hline $\begin{array}{l}\text { Kelas } 1 \\
\text { Bukan } \\
\text { kelas } 1\end{array}$ & $\begin{array}{l}\mathrm{TP}=4 \\
\mathrm{FP}=0\end{array}$ & $\begin{array}{c}\mathrm{FN}=1 \\
\mathrm{TN}= \\
10\end{array}$ & 93,3 & 100 \\
\hline & Kelas 2 & $\begin{array}{r}\text { Bukan } \\
\text { kelas } 2\end{array}$ & & \\
\hline $\begin{array}{l}\text { Kelas } 2 \\
\text { Bukan } \\
\text { kelas } 2\end{array}$ & $\begin{array}{l}\mathrm{TP}=5 \\
\mathrm{FP}=1\end{array}$ & $\begin{array}{l}\mathrm{FN}=0 \\
\mathrm{TN}=9\end{array}$ & 93,3 & 83,3 \\
\hline & Kelas 3 & $\begin{array}{l}\text { Bukan } \\
\text { kelas } 3\end{array}$ & & \\
\hline $\begin{array}{l}\text { Kelas } 3 \\
\text { Bukan } \\
\text { kelas } 3\end{array}$ & $\begin{array}{l}\mathrm{TP}=4 \\
\mathrm{FP}=1\end{array}$ & $\begin{array}{l}\mathrm{FN}=1 \\
\mathrm{TN}=9\end{array}$ & 86,6 & 80 \\
\hline
\end{tabular}

Keterangan:

TP : merupakan data positif yang terdeteksi benar.

TN : merupakan data negatif yang terdeteksi benar.

FP : merupakan data negatif yang terdeteksi positif.

FN : merupakan data positif yang masuk kedalam data negatif.

Kelas 1: merupakan kelas matang.

Kelas 2 : merupakan kelas mentah.

Kelas 3 : merupakan kelas setengah matang.

Pada Tabel 4, terlihat bahwa sensor gas TGS 2620 dan MQ 138 sangat sensitif terhadap durian kelas matang namun kurang sensitif terhadap durian setengah matang dan mentah. Akurasi yang dimiliki oleh kelas matang, setengah matang dan mentah sebesar 93,3\%; 86,6\%; 93,3\%. Akurasi rata-rata dalam klasifikasi kematangan durian sebesar 91,07\%. Akurasi tersebut sangat baik, menunjukkan bahwa metode KNN yang digunakan tepat untuk dijadikan pengkategorian kematangan durian.

\section{KESIMPULAN}

Berdasarkan hasil pengujian dan pembahasan yang telah dilakukan, didapat kesimpulan sebagai berikut.

1. Metode KNN dalam klasifikasi tingkat kematangan durian memperoleh akurasi sebesar $91,07 \%$.

2. Akurasi alat dalam memprediksi durian kelas matang, setengah matang dan mentah, masing-masing sebesar $93,3 \%$; $86,6 \%$; $93,3 \%$.

3. Semakin matang buah durian, maka semakin tinggi kadar gas dalam buah tersebut.

4. Alat deteksi kematangan durian dapat dibangun menggunakan sensor TGS 2620 dan MQ 138 berbasis Raspberry Pi 3b. 


\section{DAFTAR PUSTAKA}

[1] Herwanti, Susni. 2016. Analisis Pemasaran Durian di Desa Talang Mulya Kabupaten Pesawaran. Jurnal Ilmiah ESAI Vol. 10. No.1. Fakultas Pertanian Universitas Lampung. Lampung.

[2] Nadeak, N., R. Qurniati, W. Hidayat. Analisis Finansial Pola Tanam Agroforestri di Desa Pesawaran Indah Kecamatan Padang Cermin Kabupaten Pesawaran Provinsi Lampung. Jurnal Sylva Lestari Vol. 1. Fakultas Pertanian Universitas Lampung. Lampung.

[3] Wulandari, D., Rommy Q., dan Susni H. 2018. Efisiensi Pemasaran Durian (Duria Zibethinus) di Desa Wisata Durian Kelurahan Sumber Agung. Jurnal Sylva Lestari Vol. 6 No. 2. ISSN : 2549-5747. Fakultas Pertanian. Universitas Lampung.

[4] Sesanti, Rizka N., Hilman H., dan Nurman Abdul H. Transfer Teknologi Okulasi Durian di Kelompok Tani Harapan Baru I Kelurahan Batu Putuk Bandar Lampung. Jurnal Penelitian Pertanian Terapan Vol. 14 No. 2. Jurusan Budidaya Tanaman Pangan Politeknik Negeri Lampung. Lampung.

[4] Manik, Sry A., Ali Ibrahim H., dan Muhammad Irfan A. 2014. Analisis Kelayakan Usaha Pembibitan Durian di Kecamatan Pekalongan Kabupaten Lampung Timur. Jurnal Ilmu-Ilmu Agribisnis Vol. 2. Fakultas Pertanian Universitas Lampung. Lampung.

[6] Ashari, Sumeru. 2004. Biologi Reproduksi Tanaman Buah-buahan Komersial. Bayumedia Publishing. Malang.
[7] Sobir dan Rodame M Napitupulu. 2010. Bertanam Durian Unggul. Penebar Swadaya. Jakarta.

[8] Setiadi. 2018. Bertanam Durian. Penebar Swadaya. Jakarta.

[9] Wiryanta, Bernard T. 2008. Sukses Bertanam Durian. PT Agromedia Pustaka. Jakarta.

[10] Aak. 1997. Budidaya Durian. Kanisius. Yogyakarta.

[11] Soedarmaji, Arief dan Rifah Ediati. 2011. Identifikasi Kematangan Buah Tropika Berbasis Sistem Penciuman Elektronik Menggunakan Deret Sensor Gas Semikonduktor dengan Metode Jaringan Syaraf Tiruan. Jurnal Keteknikan Pertanian Vol. 25 No.1. IPB. Bandung.

[12] Surobramantyo, J., 2016. Rancang bangun alat pendeteksi kematangan buah durian menggunakan sensor TGS 2620 dan TGS 2600 Berbasis Arduino. Skripsi. Fakultas Teknologi dan Informatika Institut Bisnis dan Informatika STIKOM. Surabaya.

[13] Raharjo, Adi Sapto. 2019. Rancang Bangun Pengendali dan Pengawasan Gas Amonia pada Peternakan Ayam Berbasis Arduino Mega 2560 R3. Jurnal Riset Rekayasa Elektro Vol. 1 No. 2 P-ISSN : $2685-4341 \quad E$ ISSN:2685 -5313. Fakultas Ilmu Komputer Institut Informatika dan Bisnis Darmajaya. Bandar Lampung.

[14] Pratama, R., Muid A., dan Sanubary I. 2019. Perbandingan Kinerja Sensor TGS2610, MQ2 dan MQ6 pada Alat Pendeteksi Kebocoran Tabung Liquified Petroleum Gas (LPG) 
Menggunakan ATMega2560. Jurnal PRISMA FISIKA Vol. 7 No. 1 1SSN : 2337-8204. FMIPA Universitas Tanjungpura. Pontianak.

[15] Pokhum, C., Chawengkijwanich, C., and Maolanon, R. 2010. Apllication of Electronic-Nose for Identification of
Ripeness Stage of Durian. Acta Horticulture Journal No. 845 319-328.

National Nanotechnology Center. Thailand. 
Dewi Puspitasari, dkk: Aplikasi Sensor TGS2620 Dan MQ138 untuk Mendeteksi Kematangan Buah Durian Berbasis Raspberry Pi 3B 